EPJ Web of Conferences 114, 02068 (2016)

DOI: $10.1051 /$ epjconf/201611402068

C Owned by the authors, published by EDP Sciences, 2016

\title{
Determination of the heat transfer coefficient from IRT measurement data using the Trefftz method
}

\author{
Beata Maciejewska, ${ }^{1, a}$, Kinga Strąk ${ }^{2}$ and Magdalena Piasecka ${ }^{2}$ \\ ${ }^{1}$ Kielce University of Technology, Faculty of Management and Computer Modelling, 25-314 Kielce \\ ${ }^{2}$ Kielce University of Technology, Faculty of Mechatronics and Mechanical Engineering, 25-314 Kielce
}

\begin{abstract}
The paper presents the method of heat transfer coefficient determination for boiling research during FC-72 flow in the minichannels, each $1.7 \mathrm{~mm}$ deep, $24 \mathrm{~mm}$ wide and $360 \mathrm{~mm}$ long. The heating element was the thin foil, enhanced on the side which comes into contact with fluid in the minichannels. Local values of the heat transfer coefficient were calculated from the Robin boundary condition. The foil temperature distribution and the derivative of the foil temperature were obtained by solving the two-dimensional inverse heat conduction problem, due to measurements obtained by IRT. Calculations was carried out by the method based on the approximation of the solution of the problem using a linear combination of Trefftz functions. The basic property of this functions is they satisfy the governing equation. Unknown coefficients of linear combination of Trefftz functions are calculated from the minimization of the functional that expresses the mean square error of the approximate solution on the boundary. The results presented as IR thermographs, two-phase flow structure images and the heat transfer coefficient as a function of the distance from the channel inlet, were analyzed.
\end{abstract}

\section{Introduction}

Boiling heat transfer during fluid flow in minichannels is process, which it exploited the latent heat of vapourization. Due to using flow boiling process, it is possible to remove more amounts of thermal energy than in single-phase flow. Flow boiling heat transfer is often used as cooling devices or compact heat exchangers. Channels of small dimensions ensure a greater contact surface in compact heat exchangers. It also enabled work under high pressure [1]. Process of flow boiling in small channel was susceptible for various kinds of instability than in traditional size channels. In [2] the two-phase flow instability of nanofluids in a minichannel have been presented.

In literature different classifications of small channels can be found. One of the most popular it was the classification proposed by Kandlikar [3], based on hydraulic diameter of channels. According to this classification microchannels have hydraulic diameter $d_{h}$ : $10 \mu \mathrm{m} \leq d_{h} \leq 200 \mu \mathrm{m}$, minichannels: $200 \mu \mathrm{m} \leq d_{h} \leq 3 \mathrm{~mm}$ and conventional channels $d_{h}>3 \mathrm{~mm}$. Another classification was presented by Shah, who divides channels in compact heat exchangers according to their hydraulic diameter into two groups: conventional channels $\left(d_{h}>6 \mathrm{~mm}\right)$ and minichannels $\left(d_{h}<6 \mathrm{~mm}\right)$ [4].
This paper presents calculations of local heat transfer coefficients between the heated foil and the cooling liquid FC-72 flowing in a vertical minichannel, by means of the Trefftz method. This method was proposed in 1926 by E. Trefftz [5]. The Trefftz method involves approximating the solution of a problem using a linear combination of Trefftz functions. This functions strictly satisfy the governing differential equation. Additional information on the Trefftz method can be found in [6-18].

\section{Experiment}

\subsection{Experimental stand}

Experimental stand consists of several systems: the flow loop with FC-72 as a working fluid, the supply and control system, the data and image acquisition system and the lighting system. Figure 1 presents the flow loop of the experimental stand. The main elements of the this loop are: a rotary pump, a heat exchanger, a compensating tank, rotameters, a filter, and a deaerator. The data and image acquisition system consists with: a digital camera, an infrared camera, a data acquisition station, a computer with special software, and lighting systems. Experimental stand are discussed in detail in [19-21].

\footnotetext{
$\overline{{ }^{a} \text { Corresponding author: beatam@tu.kielce.pl }}$
} 


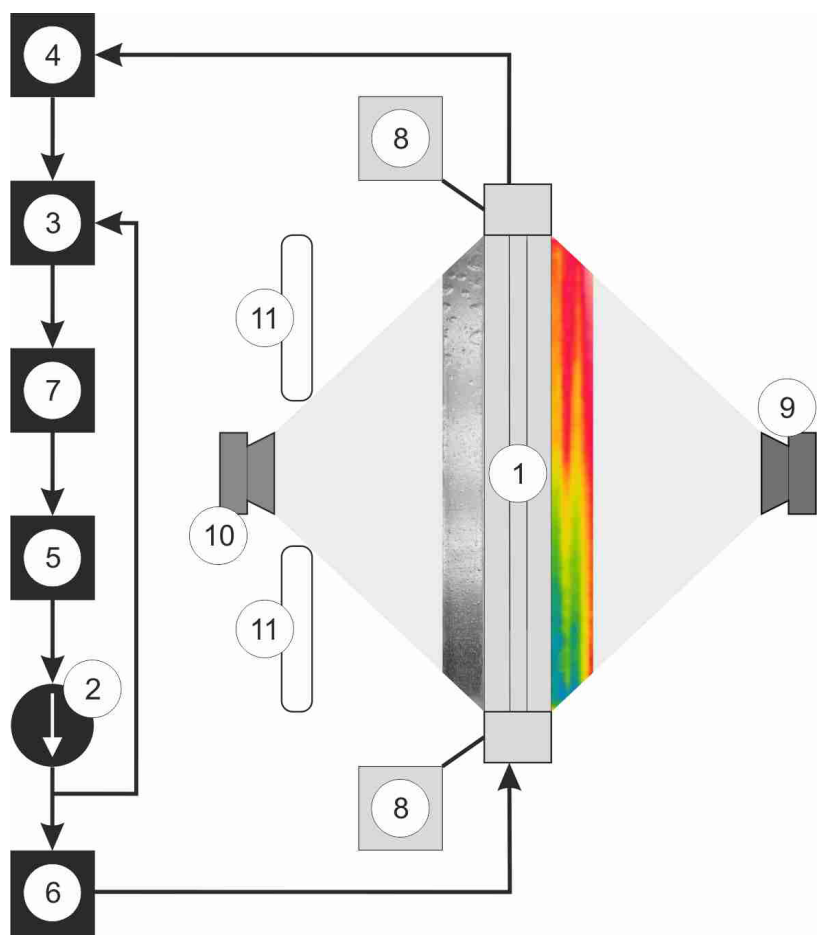

Figure 1. Schematic diagram of the flow loop with main elements of image acquisition and lighting systems of the experimental stand, 1 - testing module with a vertical minichannel; 2 - rotary pump; 3 - pressure regulator; 4 - tube-type heat exchanger, 5 - filter, 6 - rotameters; 7 - deaerator, 8 - pressure converter, 9 - digital SLR camera, 10 - infrared camera, 11 - halogen lamp.

\subsection{The testing module}

The testing module consists of two parallel rectangular, vertically-oriented minichannels, each $1.7 \mathrm{~mm}$ deep, $24 \mathrm{~mm}$ wide and $360 \mathrm{~mm}$ long, figure 2 . The heating element for FC-72 flowing in each minichannel (1) is the thin foil (2). It is possible to measure the two-dimensional temperature distribution of the heating foil in each minichannel by two contactless temperature methods, separately. In one minichannel the foil temperature is obtained by applying infrared thermography (IRT minichannel), in the other minichannel - by using liquid crystal thermography (LCT minichannel). In this study only data for IRT minichannel are taken account. In the IRT minichannel, the outer surface of the foil is coated with black paint (3) to gain an emissivity of 0.83 [22]. Foil temperature is measured by IR camera in the central, axially symmetric, part of the channel (approx. $10 \mathrm{~mm} \mathrm{x}$ $350 \mathrm{~mm}$ ). The IRT channel is reinforced on both sides with glass panels to prevent the heating foil from deforming. The other side of the minichannel is observed through the glass pane (4). In this channel occur a twophase flow during increasing the heat flux supplied to the foil. K-type thermocouples (7) and pressure converters are installed at the inlet and outlet of the minichannel.

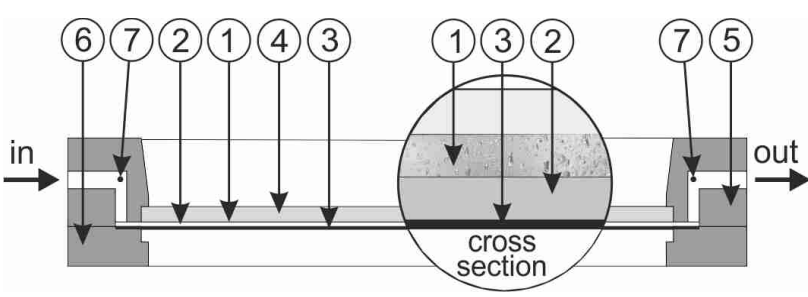

Figure 2. Schematic diagram of the testing module:

1 - IRT minichannel, 2 - heating foil, 3 - black paint layer,

4 - glass pane, 5 - channel body, 6 - front cover,

7 - thermocouple.

\subsection{Experimental methodology}

During experimental series, there is a laminar flow of FC-72 in the minichannel. When the desired pressure and flow rate are reached, there is a gradual increase in the electric power supplied to the heating foil followed by an increase in the heat flux transferred to the fluid in the channel. Data for four settings of the increasing heat flux supplied to the foil are analysed.

\subsection{Experimental uncertainties}

The images taken with a FLIR SC640 infrared camera system operating in the spectral range from $7.5 \mu \mathrm{m}$ to $13 \mu \mathrm{m}$ were recorded in a digital system with an image frequency of $30 \mathrm{~Hz}$. The accuracy of the camera is assumed as $\pm 2 \%$ of reading [23].The mean error in the measurement of the heating foil temperature using infrared thermography was estimated as $0.50 \mathrm{~K}$.

\section{Local heat transfer coefficient determination}

The local heat transfer coefficients were calculated from the following formula:

$$
\alpha(x)=\frac{-\lambda \frac{\partial T(x, \delta)}{\partial y}}{T(x, \delta)-T_{f}(x)}
$$

where $\lambda$ - coefficient of thermal conductivity of the foil, $\delta$ - foil thickness, $T$ - foil temperature, $T_{f}(x)-$ fluid temperature determined on the basis of the linear distribution of fluid temperature along the length of the minichannel from the inlet to the outlet. The foil temperature $T$ was determined by solving the inverse problem [24-28] of the heat transfer in the heating foil.

The foil temperature $T$ satisfies Poisson's equation:

$$
\nabla^{2} T=-\frac{q_{V}}{\lambda} \text { for }(x, y) \in \Omega
$$

where $\quad \Omega=\left\{(x, y) \in R^{2}: 0<x<L, \quad 0<y<\delta\right\}$, $L$-length of the minichannel and $\lambda, \delta$ defined as for Eq.(1).

The volumetric heat flux $q_{V}$ was calculated according to the formula:

$$
q_{V}=\frac{I \cdot \Delta U}{A_{F} \cdot \delta}
$$


where: $I$ - current, $\Delta U$ - voltage drop, $A_{F}-$ surface area of the heating foil determined for IRT minichannel, $\delta$ - defined as for Eq. (1).

The boundary conditions as shown in figure 3 where: $P$ - number of measurements obtained using infrared thermography (IRT) on the outer surface of the heating foil, $T_{p}^{I R T}$ - foil temperature measured by infrared thermography at the boundary $y=0$.

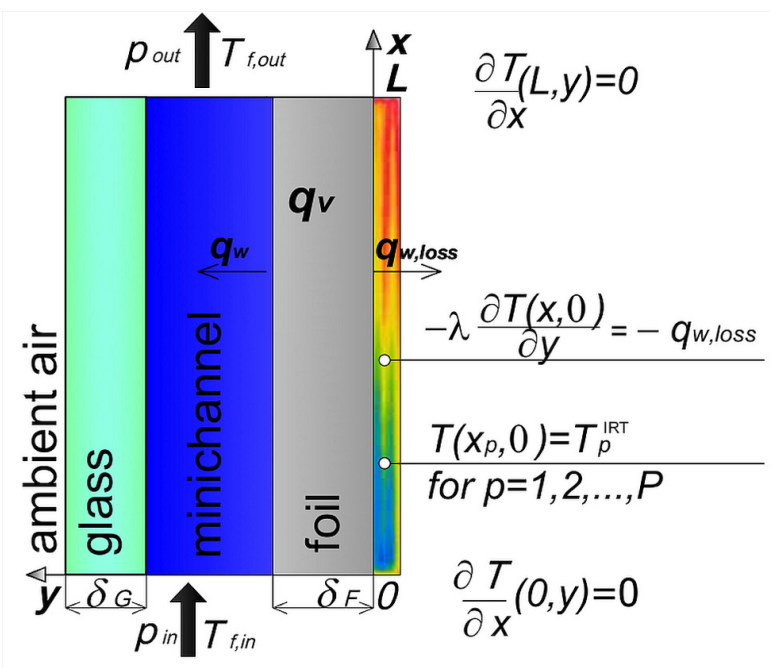

Figure 3. Boundary conditions for a two-dimensional approximation.

Heat loss to the surroundings was calculated as follows:

$$
q_{w l o s s}=\alpha_{s}\left(\max _{p=1,2, \ldots, P} T_{p}^{I R T}-T_{s}\right)
$$

where: $\alpha_{s}$ - local values of the heat transfer coefficient at the interface between the heating foil and the surroundings [29], $T_{s}$ - ambient temperature, $T_{p}^{I R T}$ and $P$ defined as for Eq.(2).

In domain $\Omega$, the temperature $T$ was approximated by means of the linear combination of Trefftz functions:

$$
T(x, y)=u(x, y)+\sum_{i=1}^{N} a_{i} v_{i}(x, y)
$$

where: $u(x, y)$ - particular solution of Eq. (2), $v_{i}(x, y)$ the Trefftz functions.

The unknown coefficients $a_{i}$ were calculated by minimizing the functional:

$$
\begin{aligned}
J=\int_{0}^{\delta}( & \left(\frac{\partial T}{\partial x}(0, y)^{2}+\left(\frac{\partial T}{\partial x}(L, y)\right)^{2}\right) d y+ \\
+ & \int_{0}^{\delta}\left(\frac{\partial T}{\partial y}(x, 0)-\frac{q_{w, \text { loss }}}{\lambda}\right)^{2} d x+ \\
& +\sum_{p=1}^{P}\left(T\left(x_{p}, 0\right)-T_{p}^{I R T}\right)^{2}
\end{aligned}
$$

\section{Results}

Figure $4 \mathrm{a}$ shows the infrared thermographs of the complete experimental series. Four heat flux settings were selected for further analysis. Figure 4b,c shows the data for these settings in the form of IR thermograms of the heating foil surface and two-phase flow images, respectively.

Heat transfer processes were analysed using the experimental data - the temperature of the heating foil, two-phase flow structure images, the temperature of the working fluid, the pressure in the channel - and the plots of the heat transfer coefficients (figure 5) as a function of the distance from the minichannel inlet. The heat transfer coefficients calculated using the two-dimensional model were discussed. The calculation results were presented for four settings of the increasing heat flux supplied to the heating foil.

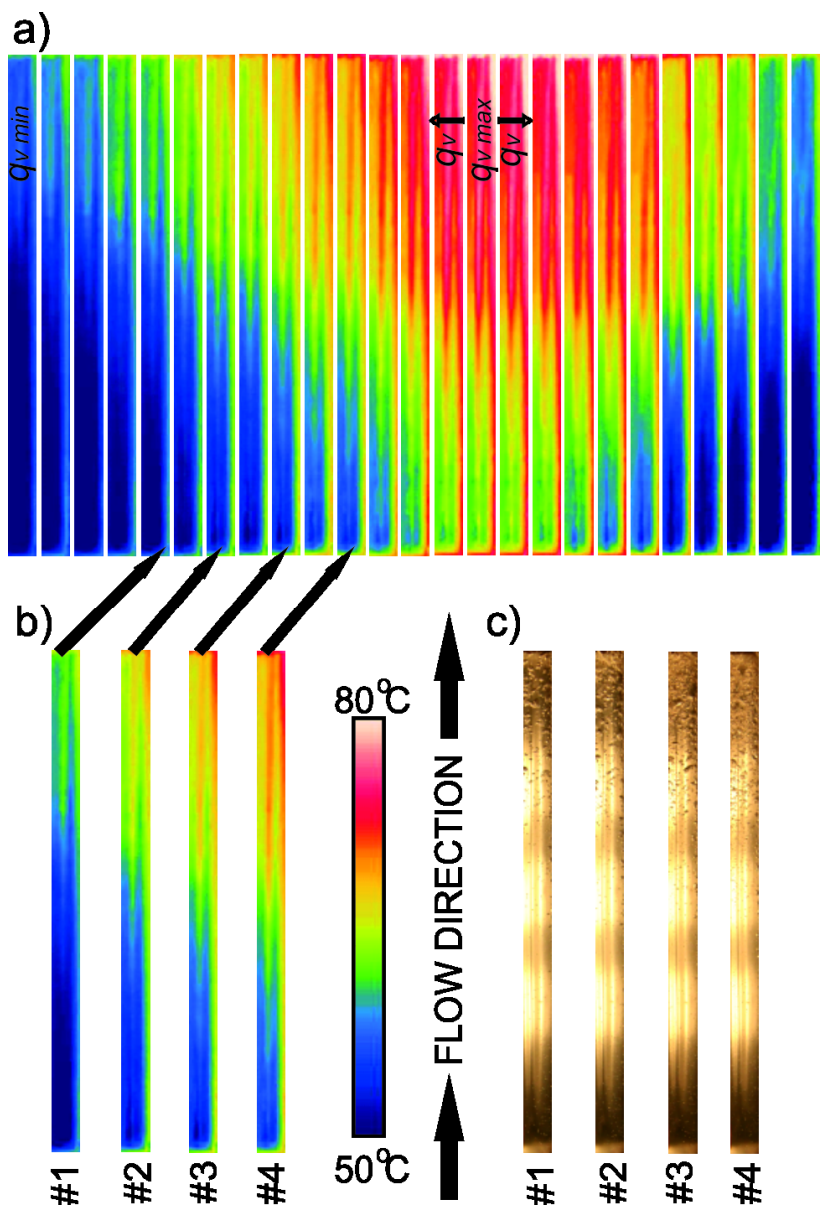

Figure 4. a,b) Thermographs of the heating foil surface measured by infrared thermography, data for: the complete experimental series (a), selected settings of the heat flux (b); c) two-phase flow structure images - data for selected settings of the heat flux; experimental parameters: average mass flux of $164 \mathrm{~kg} \mathrm{~m}^{-2} \mathrm{~s}^{-1}$, average inlet pressure of $165 \mathrm{kPa}$, average inlet liquid subcooling of $45.8 \mathrm{~K}$, volumetric heat fluxes: \#1) $q_{V}=9.60 \cdot 10^{4} \mathrm{~kW} \mathrm{~m}^{-3}$; \#2) $q_{V}=1.06 \cdot 10^{5} \mathrm{~kW} \mathrm{~m}^{-3}$; \#3) $q_{V}=1.17 \cdot 10^{5} \mathrm{~kW} \mathrm{~m}^{-3}$; \#4) $q_{V}=1.28 \cdot 10^{5} \mathrm{~kW} \mathrm{~m}^{-3}$.

In 2D approach, for approximation of the foil temperature, 12 Trefftz functions defined by the following formulas were used [12]:

$$
v_{n}(x, y)=\sum_{k=0}^{\left[\frac{n}{2}\right]} \frac{(-1)^{k} x^{n-2 k} y^{2 k}}{(2 k) !(n-2 k) !}, n=0,1, \ldots, 7
$$




$$
\begin{aligned}
& v_{m}(x, y)=\sum_{k=0}^{\left[\frac{m-1}{2}\right]} \frac{(-1)^{k} x^{m-2 k-1} y^{2 k+1}}{(2 k+1) !(m-2 k-1) !}, \\
& m=1,2, \ldots, 8
\end{aligned}
$$

as a particular solution of Eq. (2)

$$
u(x, y)=-\frac{q_{V}\left(x^{2}+y^{2}\right)}{4 \lambda_{F}}
$$

was accepted.

The IRT temperature measurements allowed determining the foil temperature over the entire minichannel length, which was not the case in the authors' earlier works [20,21,30,31], where temperatures were measured using liquid crystal thermography (LCT) limited by the active band of the liquid crystal mixture.

The values of local heat transfer coefficients (see figure 5) indicate their rapid increase in the boiling region. Increasing values of the vapour quality were usually obtained by increasing the applied heat flux. Local vapour quality increases with increasing distance from the minichannel inlet [20]. The highest heat transfer coefficient for all heat flux settings was achieved at the minichannel outlet for which vapour quality was the highest. This observation is consistent with some of the findings by other researchers $[32,33]$ but not with the previous research results reported by the authors of this paper. The onset of boiling was accompanied by a sharp increase in the heat transfer coefficient. In fully developed nucleate boiling, the heat transfer coefficient was the highest but then it decreased sharply with an increase in the vapour quality. Very high values of the local heat transfer coefficient at the minichannel outlet were typically determined for the saturated boiling region. In the subcooled boiling region, significantly lower heat transfer coefficients were obtained [20,21,30]. In the present study, for the experimental data, a sharp increase in heat transfer coefficient was observed at the distance of $0.25 \mathrm{~m}$ to $0.35 \mathrm{~m}$ from the minichannel inlet, but the experimental data do not indicate that the saturated boiling region developed (except the narrow region near the minichannel outlet). However, the analysed region overlapped with the area where an increase in the number and size of the generated bubbles was detected (see figure 4c). Furthermore, no 'nucleation hysteresis' was observed while increasing the heat flux to the heating foil. It is known that under certain conditions, a considerable rise in the wall temperature can occur above the saturation point before the boiling begins. This "temperature overshoot" also referred to as "superheated excursion" or "nucleation hysteresis" is characteristic for highly wetting dielectric fluids (e. g. refrigerants) [33-38]. The nucleation hysteresis is mainly due to the local distribution of nucleation sites and the wetting characteristics of the used refrigerant [33]. The abrupt decrease in heating surface temperature results from the vapor bubbles spontaneous formation in the wall adjacent layer. They function as internal heat sinks, absorbing significant amount of energy transferred to the liquid [35-38].
The untypical heat transfer coefficient plot and the fact that 'nucleation hysteresis' did not occur may have been due to large pressure fluctuations recorded for the increasing heat flux. During the experimental series, extremely large pressure fluctuations were measured at the outlet of the channel. Increasing local pressure may have caused disturbance and turbulent flow. This probably increased the local bulk fluid temperature, resulting in high local heat transfer coefficients at the outlet of the minichannel.

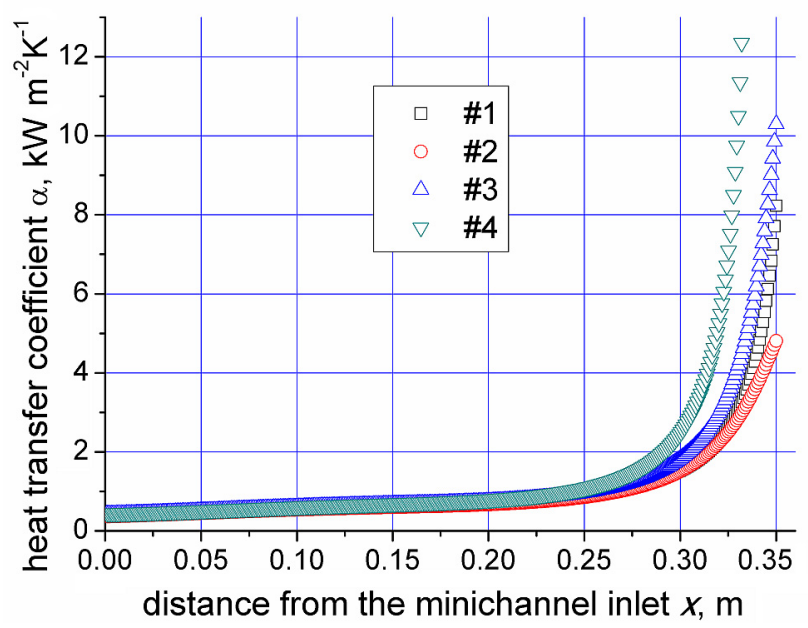

Figure 5. Heat transfer coefficient as a function of the distance from the minichannel inlet, obtained by using IRT.

\section{Conclusions}

The paper presents the method of heat transfer coefficient determination for boiling research during FC-72 flow in a minichannel. Local values of the heat transfer coefficient were calculated from the Robin boundary condition. The foil temperature distribution and the derivative of the foil temperature were obtained by solving the twodimensional inverse heat conduction problem, due to measurements obtained by infrared thermography. Calculations was carried out by the method based on the approximation of the solution of the problem using a linear combination of Trefftz functions.

The results were presented as IR thermographs and two-phase flow structure images. The heat transfer coefficient were given as a function of the distance from the channel inlet. The phenomenon of "nucleation hysteresis" was not observed. Local heat transfer coefficients increased rapidly in the developed boiling region. The greatest value of the coefficients was achieved at the minichannel outlet for all heat flux settings under analysis. Large pressure fluctuations recorded while increasing the heat flux may have been a factor in the non-occurrence of "nucleation hysteresis" and may have contributed to the untypical plot of the heat transfer coefficient. 


\section{Acknowledgements}

The research reported herein was supported by a grant from the National Scientific Center (No. DEC2013/09/B/ST8/02825).

\section{References}

1. S. Saisorn, J. Kaew-On, S. Wongwises, Exp. Therm. Fluid Sci. 46, 232-244 (2013)

2. L. Yu, A. Sur, D. Liu, J. Heat Tran. 137 (5), (2015)

3. S. G. Kandlikar, Exp. Therm. Fluid Sci. 26, 389-407 (2002)

4. R. K. Shah, Classification of Heat Exchangers, Heat Exchangers-Thermal/Hydraulic Fundamentals and Design (Hemisphere Publishing Washington DC, 9-46, 1981)

5. E. Trefftz, Proc. Int. Kongress für Technische Mechanik, Zürich, 131-137 (1926)

6. E. Kita, N. Kamiya, Adv. Eng. Softw. 24, 3-12 (1995)

7. V. Kompis, F. Konkol, M. Vasko, Comp. Assisted Mech. Eng. Sci. 8, 385-395 (2001)

8. I. Herrera, Numer. Meth. Partial Diff. Eq. 16, 561$580(2000)$

9. S. Hożejowska, R. Kaniowski, M. E. Poniewski, Int. J. Numer. Method Heat Fluid Flow 24, 811-824 (2014)

10. K. Grysa, A. Maciąg, A. Pawińska, Int. J. Heat Mass Tran. 55, 7336-7340 (2012)

11. B. Movahedian, B. Boroomand, S. Soghrati, Eng. Anal. Bound. Elem. 37, 868-883 (2013)

12. M. J. Ciałkowski, A. Frąckowiak, J. Therm. Sci. 11, 148-162 (2002)

13. M. J. Ciałkowski, K. Grysa, J. Inv. Ill-Posed Problems 18, 595-616 (2010)

14. M. J. Ciałkowski, A. Frąckowiak, K. Grysa, J. Inv. Ill-Posed Problems 15, 347-364 (2007)

15. M. J. Ciałkowski, A. Frąckowiak, K. Grysa, Int. J. Heat Mass Tran. 50, 2170-2181 (2007)

16. A. P. Zieliński, Afdv. Eng. Softw. 24, 147-155 (1995)

17. A. Frąckowiak, J. V. Wolfersdorf, M. Ciałkowski, Int. J. Heat Mass Tran. 54, 1236-1243 (2011)

18. M. S. Karaś, A. P. Zieliński, Commun. Num. Methods Eng. 24, 605-625 (2008)

19. M. Piasecka, Heat Tran. Eng. 35 (10), 903-912 (2014)

20. M. Piasecka, Int. J. Refrig. 56, 198-212 (2015)

21. M. Piasecka, Ann. Nucl. Energy 73, 282-293 (2014)

22. T. Orzechowski, Heat transfer on ribs with microstructured surface, Monographs, studies, hearings 39 (in Polish) ( the Publishing House of the Kielce Univ. Techn., Kielce, Poland, 2003)

23. User's manual ThermaCam B640, P640, SC640, Publ. No 155850 Rev.a 201-ENGLISH (EN) (2007)

24. J. V. Beck, B. Blackwell, C. R. St Clair, Inverse heat conduction. Ill-posed Problems (Wiley - Interscience Publ., New York, 1985)

25. O. M. Alifanow, Inverse heat transfer problems (Springer-Verlag, Berlin, 1994)
26. K. Kurpisz, A. J. Nowak, Inverse Thermal Problems, International Series on Computational Mechanics Publications (Southampton, UK and Boston, USA, 1995)

27. M. N. Ozisik, H. R. B Orlande, Inverse heat transfer: fundamentals and applications (Taylor \& Francis, New York, 2000)

28. A. N. Tikhonov, V. Y. Arsenin, Solution of ill-posed problems (Wiley, New York, 1977)

29. Y. A. Cengel, and R.H. Turner, Fundamentals of thermal-fluid sciences (McGraw-Hill Higher Education, International Edition 2001)

30. M. Piasecka, B. Maciejewska, Exp. Therm. Fluid Sci. 44, 23-33 (2013)

31. M. Piasecka, Int. J. Heat Mass Tran. 81, 114-121 (2015)

32. Y.M. Lie, F.Q. Su, R.L. Lai, T.F. Lin, Int. J. Heat Mass Tran. 49, 207-218 (2006)

33. L. Saraceno, G.P. Celata, M. Furrer, A. Mariani, G. Zummo, Int. J. Therm. Sc. 53, 35-41 (2012)

34. G. P. Celata, M. Cumo, T. Setaro, Exp. Heat Tran. 5, 253-275 (1992)

35. M. Piasecka, M. E. Poniewski, Heat Tran. Eng. 25 (3), 44-51 (2004)

36. S. Hożejowska, M. Piasecka, Heat Mass Tran. 50, 1053-1063 (2014)

37. Z. Bilicki, Int. J. Heat Mass Tran. 26, 559-565 (1983)

38. T. Bohdal, Exp. Heat Tran. 14, 199-215 (2001) 